\title{
Pengaruh Hypnobirthing Terhadap Tingkat Nyeri Dan Kemajuan Persalinan Pada Ibu Bersalin Di Bpm Kota Cimahi
}

\author{
Indria Astuti ${ }^{*}$, Noviyanti ${ }^{2}$ \\ ${ }^{1,2}$ Stikes Jend. A. Yani Cimahi, Indonesia
}

Informasi Artikel:

Diterima: September, 2015

Disetujui: Oktober, 2015

${ }^{*}$ Korespondensi penulis. ind_ast@yahoo.com

\begin{abstract}
ABSTRAK
Sekitar 90\% penyebab kematian ibu adalah komplikasi obstetrik yang terjadi saat persalinan. Salah satu komplikasi obstetrik adalah persalinan yang berlangsung lama yang disebabkan kontraksi uterus yang tidak adekuat. Salah satu upaya mempertahankan kontraksi uterus adalah dengan tehnik hypnobirthing. Penelitian ini bertujuan untuk mengetahui pengaruh hypnobirthing terhadap tingkat nyeri dan kemajuan persalinan.
\end{abstract}

Jenis penelitian yang digunakan adalah True Experiment yang termasuk ke dalam Posttest Only Control Design. Populasi penelitian ini adalah ibu bersalin di salah satu BPM di Kota Cimahi sebanyak 30 responden. Teknik pengambilan sampel dengan menggunakan purposive sampling yang berdasarkan kriteria penelitian. Teknik pengumpulan data dengan menggunakan lembar observasi dan partograf, dan analisis data menggunakan bivariat dengan Uji T-test independent.

Hasil analisis yang diperoleh menunjukkan bahwa nilai $\mathrm{p}$ tingkat nyeri adalah 0.001 , yang artinya bahwa terdapat pengaruh hypnobirthing yang signifikan terhadap penurunan intensitas nyeri dan 0.038 , yang artinya bahwa terdapat pengaruh hypnobirthing yang signifikan terhadap kemajuan persalinan.

Kata kunci: Hypnobirthing,Tingkat Nyeri Persalinan, kemajuan persalinan

\section{ABSTRACT}

Approximately $90 \%$ of causes of maternal deaths occur during delivery due to obstetric complications. One of the complications is prolonged labor caused by inadequate contractions. One method to maintain the uterine contractions is with hypnobirthing. The objective of this research was to determine the effects of hypnobirthing on the level of pain and the progress of labor.

This was a true experiment with a posttest only control design. The population was women delivering at BPM at the Cimahi amounting to 30 respondents. The sampling technique used accidental sampling based on research criteria. Data collection method used observation sheets and partograph. The data were then analyzed using bivariate analysis with T-test independent.

The results showed that the p-value obtained was 0.001 and 0.038 , respectively, meaning that there was a significant relationship between hypnobirthing and decreased pain intensity and between hypnobirthing and the progress of labor.

Keywords: Hypnobirthing, Pain Maternal Intensity, the progress of labor. 


\section{PENDAHULUAN}

Persalinan merupakan kejadian fisiologis dan normal yang dialami oleh wanita. Persalinan yang tidak dapat ditangani dengan baik dapat menyebabkan proses persalinan tidak berlangsung dengan lancar sehinga persalinan berlangsung lama.

Power atau kekuatan ibu merupakan salah satu yang dapat mempengaruhi persalinan untuk berlangsung lama. Kala I yang lama disebabkan karena tidak adekuatnya kontraksi uterus (His) yang menyebabkan pembukaan berjalan lambat. Persalinan yang lama dapat menyebabkan ibu mengalami kelelahan sehingga kehabisan tenaga. Dampaknya adalah bahwa kontraksi uterus semakin tidak adekuat dan selanjutnya kondisi ini dapat menyebabkan kegagalan kemajuan persalinan (Prawirohardjo, 2006; Harahap, 2009; Oxom, 2010). Tidak adekuatnya kondisi uterus akan menyebabkan terjadinya perdarahan intrapartum dan postpartum yang merupakan penyebab kematian terbesar. Kondisi lain yang mempengaruhi lama persalinan adalah kondisi psikologis yang meliputi persepsi ibu pada rasa nyeri dan cemas saat persalinan (Prawirohardjo, 2002 ).

Rasa nyeri pada persalinan adalah nyeri kontraksi uterus yang dapat mengakibatkan peningkatan aktivitas sistem syaraf simpatis. Nyeri yang hebat pada persalinan dapat menyebabkan perubahanperubahan fisiologi tubuh, seperti kenaikan tekanan darah, kenaikan denyut jantung, dan kenaikan laju pernafasan, dan apabila tidak segera diatasi, maka keadaan ini akan meningkatkan rasa khawatir, tegang, takut dan stres. Peningkatan konsumsi glukosa tubuh pada ibu bersalin yang mengalami stres menyebabkan kelelahan dan sekresi katekolamin yang menghambat kontraksi uterus, dan hal tersebut menyebabkan persalinan menjadi lama (Bobak, 2005, Cuningham 2004).

Salah satu upaya untuk mempertahankan kontrakasi uterus pada saat persalinan adalah dengan menggunakan tehnik hypnobirthing. Metode hypnobirthing merupakan kombinasi antara proses kelahiran alami dengan hypnosis untuk membangun persepsi positif dan rasa percaya diri serta menurunkan ketakutan, kecemasan dan ketegangan, dan panik sebelum, selama dan setelah persalinan). Salah satu tehniknya adalah autohipnosis (selfhipnosis) atau swasugesti dalam menghadapi dan menjalani kehamilan serta persiapan melahirkan sehingga para wanita hamil mampu melalui masa kehamilan dan persalinannya dengan cara yang alami, lancar, dan nyaman (tanpa rasa sakit), dan yang lebih penting lagi adalah untuk kesehatan jiwa dari bayi yang dikandungnya. Ketika wanita yang melahirkan terbebas dari rasa takut, otot tubuhnya, termasuk otot rahim, akan mengalami relaksasi yang membuat proses kelahiran menjadi lebih mudah dan bebas stress (Kuswandi 2013; Semple, 2015).

Hypnobirthing bertujuan agar ibu dapat melahirkan dengan nyaman, cepat, dan lancar dan menghilangkan rasa sakit saat melahirkan tanpa bantuan obat bius apapun. Metode ini juga lebih menekankan kelahiran dengan cara positif, lembut, aman, dan mudah (Kuswandi, Aprillia, 2010).

Berdasarkan hasil penelitian Lu, dkk (2009), persalinan yang lama terjadi terutama pada kala II yang merupakan faktor penting yang menyebabkan perdarahan postpartum. Dampak lain adalah bahwa janin tertahan dan tertekan lebih lama pada jalan lahir, sehingga mengalami kondisi gawat janin akibat hipoksia uteri (Bobak, 2005; Winkjosastro 2005; Cunningham, 2004). Kondisi lain yang mempengaruhi lama persalinan adalah kondisi psikologis yang meliputi persepsi ibu pada rasa nyeri dan cemas saat persalinan. Nyeri bersalin dapat menimbulkan respons fisiologis yang mengurangi kemampuan rahim saat kontraksi, sehingga bisa memperpanjang waktu persalinan

Berdasarkan studi pendahuluan di beberapa lahan praktik, ibu bersalin mengalami rasa khawatir dan takut pada proses persalinan yang dialaminya sehingga dapat berdampak pada kemajuan persalinan. Bidan sebagai tenaga pelayanan kesehatan khususnya dalam bidang kesehatan ibu dan anak merupakan faktor penting dalam proses 
persalinan sebagai penolong persalinan. Bidan juga dituntut untuk dapat menjadi pelaku inovasi dengan menggunakan metode-metode terbaru untuk melakukan asuhan sayang ibu, salah satunya yaitu metode hypnobirthing. Penelitian ini dilakukan untuk mengetahui pengaruh tehnik hypnobirthing terhadap tingkat nyeri persalinan dan kemajuan persalinan pada ibu bersalin.

\section{BAHAN DAN METODE}

Penelitian ini adalah penelitian true experiment, dengan memberikan perlakuan/ intervensi pada subjek penelitian. Jenis rancangan yang digunakan adalah Posttest Only Control, yaitu pemilihan kelompok penelitian yang dilakukan secara random baik kelompok kontrol maupun kelompok perlakuan. Setelah dipilih, kelompok perlakuan diberikan intervensi dan kelompok kontrol tidak. Setelah itu, kedua kelompok diobservasi dengan instrumen Visual Analogue Scale (VAS) dan partograf. Rancangan penelitian ini adalah sebagai berikut:

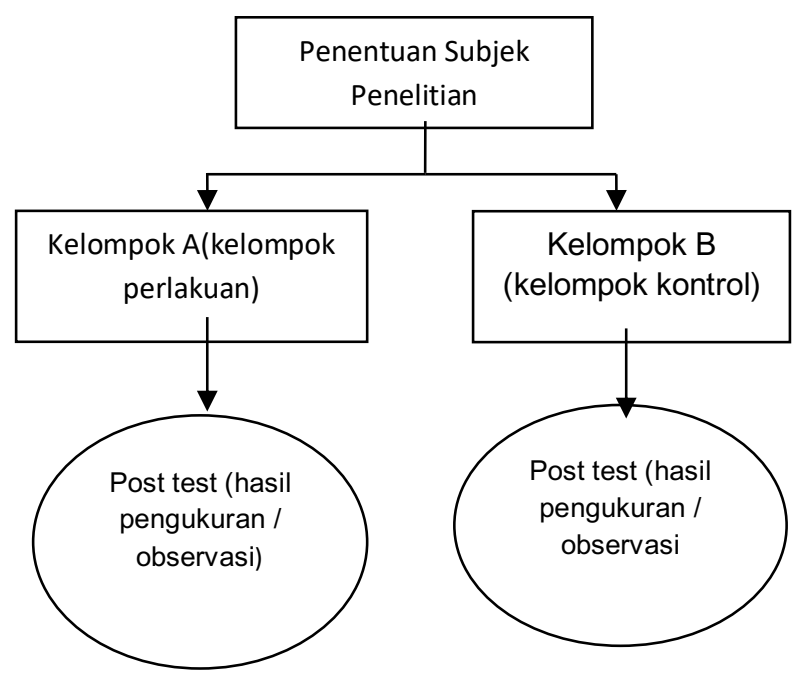
Gambar 1. Bagan Penelitian True Experiment
Rancangan Posttest Only Control

Sampel dalam penelitian ini adalah ibu bersalin di salah satu BPM Kota Cimahi yang diambil dengan menggunakan teknik purposive sampling sebanyak 30 orang. Kelompok Kontrol berjumlah 15 orang dan kelompok perlakukan berjumlah 15 orang. Tempat penelitian dilaksanakan di salah satu BPM
Kota Cimahi pada bulan Desember 2014 s.d Maret 2015. Data yang digunakan dalam penelitian ini berupa data primer dengan teknik pengumpulan data menggunakan wawancara dengan menggunakan lembar observasi.

Indikator pengukuran kemajuan persalinan dalam hitungan menit dimana waktu yang digunakan saat proses persalinan spontan mulai dari kala 1 fase aktif sejak pasien datang sampai pembukaan lengkap dan intesitas nyeri dengan menggunakan VAS yaitu; 1) $0=$ tidak nyeri; 2) 1-3=nyeri ringan 3)4-6=nyeri sedang; 4) 7 - =nyeri berat; 5) $=10=$ nyeri sangat berat

Data yang dikumpulkan adalah data primer yang didapat langsung dari hasil penelitian di lapangan (field research) dengan menggunakan instrumen penelitian VAS dan Partograf. Setelah peneliti mendapatkan surat izin dari BPM untuk melakukan penelitian, peneliti selanjutnya melakukan informed consent kepada responden. Setelah itu, peneliti melakukan hypnobirthing pada ibu bersalin dan mengukur tingkat nyeri persalinan dan kemajuan persalinan untuk kelompok studi dengan perlakuan, dan mengukur secara langsung tanpa melakukan hypnobirthing saat proses persalinan untuk kelompok studi kontrol.

\section{HASIL DAN PEMBAHASAN}

Pada bab ini akan diuraikan mengenai hasil penelitian dan pembahasan mengenai pengaruh hypnobirthing terhadap tingkat nyeri dan kemajuan persalinan yang dapat dilihat pada tabel 1 :

Tabel 1.

Pengaruh Hypnobirthing Terhadap Intensitas Nyeri Persalinan

\begin{tabular}{lccccc}
\hline \hline Variabel & N & Mean & SD & SE & p-value \\
\hline Tidak & 15 & 7,67 & 1,345 & 0,347 & 0,001 \\
Hyno & 15 & 5,73 & 1,534 & 0,396 & \\
Hypno & & & & & \\
\hline \multicolumn{2}{l}{ Sumber: Data Primer } & & &
\end{tabular}

Sumber: Data Primer 
Dari Tabel 1 diperoleh P value 0.001, yang berarti berarti bahwa terdapat pengaruh yang signifikan antara hypnobirthing dengan intensitas nyeri persalinan pada ibu bersalin. Hal ini terlihat dari menurunya skala nyeri pada 30 sampel penelitian pada kelompok yang dilakukan hypnobirthing. Pada kelompok yang tidak diberikan hypnobirthing, sebagian besar responden mengalami nyeri berat $(66,7 \%)$, yang diikuti nyeri sedang $(26,7 \%)$, dan nyeri sangat berat $(6,7 \%)$. Pada kelompok yang diberi hypnobirthing, sebagian besar responden mengalami nyeri sedang $(60 \%)$, yang diikuti nyeri berat $(26,7 \%)$, dan nyeri ringan $(13,3 \%)$.

Metode Hypnobirthing menekankan pada munculnya sugesti positif, perasaan tenang, dan relaks yang membuat nyaman. Saat kondisi tenang dan relaks, maka secara otomatis otak akan mengalirkan hormon endorfin yang mengurangi rasa sakit dan memberi rasa nyaman dan relaks. Namun, apabila rasa panik, takut, atau stres saat persalinan semakin menguat, maka otak akan mengalirkan zat yang menutup pengeluaran hormon endorfin. Semakin takut seseorang saat melahirkan, semakin luar biasa pula sakit yang akan dirasakan. Hypnobirthing akan membawa ibu untuk sama sekali tidak memikirkan dan merasakan nyeri yang ditimbulkan oleh kontraksi rahim. Kontraksi adalah hal alami yang pasti terjadi selama persalinan. Namun, hypnobirthing mampu membuat ibu tetap rileks dan tidak panik sehingga tanpa terasa nyeri proses kelahiran berjalan lancar dan tiba-tiba saja tangis bayi sudah terdengar. Ketika dalam keadaan rileks, alam bawah sadar ibu akan mengatur keselarasan tubuh dan menghasilkan anestesi atau pembiusan yang alami pada ibu yaitu hormon endorfin. (Mongan 2007, Aprilia 2010, Semple, 2015).

Hal ini sejalan dengan penelitian yang dilakukan Melyana, dkk. (2009) dalam dengan judul pengaruh metode hypnobirthing terhadap intensitas nyeri kala I persalinan normal di BPS Kota Semarang. Penelitian tersebut menunjukan bahwa sebagian besar responden pada kelompok yang tidak diberi hypnobirthing mengalami intensitas nyeri berat sebanyak $70 \%$ dan nyeri ringan sebanyak $30 \%$. Pada kelompok yang diberi hypnobirthing, sebagian besar responden mengalami nyeri ringan sebanyak $66 \%$, nyeri sedang sebanyak $27 \%$, dan nyeri berat sebanyak 7\%. Penelitian ini didukung juga dengan hasil penelitian Marfu'ah tahun 2010 tentang perbedaan intensitas nyeri pada responden yang dilakukan hypnobirthing pada ibu bersalin primipara pada persalinan normal. Hasil penelitian tersebut diketahui bahwa, dari 30 responden yang diberi hypnobirthing, responden yang menunjukkan nyeri berat adalah $40 \%$, nyeri sedang $53,3 \%$, dan nyeri ringan 3,3\% (Marfu'ah, 2010).

Tabel 2.

\section{Pengaruh Hypnobirthing terhadap kemajuan persalinan (dihitung dalam menit)}

\begin{tabular}{lccccc}
\hline \multicolumn{1}{c}{ Variabel } & Mean & SD & SE & P Value & N \\
\hline Tidak di Hypno & 100 & 59,642 & 5,399 & 0,038 & 15 \\
Hypno & 60,67 & 34,737 & 3,969 & & 15
\end{tabular}

Sumber: Data Primer

Dari tabel 2 didapatkan hasil analisis bahwa rata-rata lama persalinan pada ibu bersalin tanpa diberikan hypnobirthing adalah dengan kemajuan persalinan 100 menit dan rata-rata ibu bersalin dengan hynobirthing adalah 66,7 menit. Nilai $\mathrm{p} 0.038$ berarti bahwa ada pengaruh hypnobirthing terhadap kemajuan persalinan pada ibu bersalin.

Hal ini sejalan dengan penelitian Nuraisyah S bahwa terdapat pengaruh yang signifikan tehnik hypnobirthing terhadap lama proses persalinan dengan nilai $\mathrm{p}=0,034$ dan didukung oleh penelitian Mahmudah bahwa terdapat pengaruh hypnobirthing dengan lama persalinan dengan nilai $\mathrm{p}=0,011$.

Metode hypnobirthing dapat memberikan dukungan mental yang berdampak positif bagi keadaan psikis ibu, yang berpengaruh pada kelancaran proses persalinan. Pada saat bersalin, hormon stres, seperti adrenalin, berinteraksi dengan reseptor-beta di dalam otot uterus dan menghambat kontraksi dan memperlambat persalinan sehingga ibu bersalin membutuhkan kondisi yang rileks dan nyaman. Saat kondisi tenang dan relaks, alam bawah sadar ibu 
akan mengatur keselarasan tubuh dan menghasilkan anestesi atau pembiusan yang alami pada ibu, yaitu hormon endorfin. Hipnobirthing terbukti efektif dalam untuk memberikan rasa nyaman pada saat persalinan

\section{KESIMPULAN}

Berdasarkan hasil penelitian yang dilakukan di BPM Kota Cimahi tahun 2015, hipnobirthing memiliki pengaruh yang signifikan dengan tingkat nyeri dan kemajuan persalinan pada ibu bersalin dengan nilai $\mathrm{p}$ berturut-turut 0,001 dan 0,038

\section{DAFTAR PUSTAKA}

Aprilia, Y. (2010). Hipnostetri. Rileks Nyaman dan Aman saat Hamil dan Melahirkan. Jakarta. Gagas Media

Bobak, Irena. (2005). Maternity Nursing. Jakarta:EGC. .

Cunningham, F.Gary. (2004). Obstetri William. Jakarta : EGC

Harahap D,(2009). Pengaruh tehnik relaksasi hypnosis diri terhadap tingkat nyeri dan lama persalinan pada ibu primipara. Tesis FIK UI

Hidayat, A.A. (2007). Metode Penelitian Kebidanan dan Teknik Analisa Data. Jakarta:Salemba Medika

Kuswandi, Lany. (2013). Hynobirthing A Gentle Way to Give Birth. Cetakan I. Pustaka Bunda. . Jakarta.

Marfuah., S.. (2010). Perbedaan intensitas nyeri kala 1 persalinan normal pada ibu primipara yang diberikan hypnoterapy di BPS Yohana dan Sumarni Semarang tahun 2010: Tidak dipublikasikan.

Mahmudah S. (2013) Pengaruh Pemberian Hypnobirthing dengan lama persalinan kala I Fase Aktif Pada Ibu Bersalin di BPS Prita . Stikes ngudi Waluyo.
Melyana, dkk. (2009). Pengaruh Metode Hypnobirthing terhadap Intensitas Nyeri Kala I Persalinan Normal di BPS Kota Semarang. Semarang : Politeknik Kesehatan Semarang. Tidak dipublikasikan

Mongan. (2007). Hypnobrithing. Jakarta : PT Bhuana Ilmu popular.

Nuraisyah S (2012). Pengaruh tehnik Hypnobirthing Terhadap Lamanya Proses Persalinan Sumut: Kebidanan Fakultas Keperawatan UNSU

Oxom \& Forte. (2010). Ilmu kebidanan: Patofisiologi \& Fisiologi Persalinan (E.d.I). Yogyakarta: Andi;Yem

Prawirohardjo, Sarwono.(2006). Ilmu Kebidanan. Jakarta: Yayasan Bina Pustaka

Prawirohardjo, Sarwono. 2002. Asuhan Neonatal dan Maternal. Jakarta : EGC

Semple A, 2015. Self Hynopsis for Labour and Birth. Research Overview 